\title{
Differences in the Ice Particle Shattering Impact on the CIP Measurements in the Stratiform Cloud Region and the Embedded Convection Region
}

\author{
Minsong Huang 1,2,3,4
}

1 Key Laboratory of Cloud-Precipitation Physics and Severe Storms, Institute of Atmospheric Physics, Chinese Academy of Sciences, Beijing 100029, China; mission@mail.iap.ac.cn

2 Key Laboratory of Meteorological Disaster (KLME), Ministry of Education \& Collaborative Innovation Center on Forecast and Evaluation of Meteorological Disasters (CIC-FEMD), Nanjing University of Information Science \& Technology, Nanjing 210044, China

3 Jiangsu Key Laboratory of Meteorological Observation and Information Processing, Nanjing University of Information Science and Technology, Nanjing 210044, China

4 Collaborative Innovation Center of Atmospheric Environment and Equipment Technology, Nanjing University of Information Science and Technology, Nanjing 210044, China

check for updates

Citation: Huang, M. Differences in the Ice Particle Shattering Impact on the CIP Measurements in the Stratiform Cloud Region and the Embedded Convection Region. Water 2021, 13, 2322. https://doi.org/ $10.3390 / w 13172322$

Academic Editor: Luca Giovanni Lanza

Received: 27 May 2021

Accepted: 22 August 2021

Published: 25 August 2021

Publisher's Note: MDPI stays neutral with regard to jurisdictional claims in published maps and institutional affiliations.

Copyright: (C) 2021 by the author. Licensee MDPI, Basel, Switzerland. This article is an open access article distributed under the terms and conditions of the Creative Commons Attribution (CC BY) license (https:// creativecommons.org/licenses/by/ $4.0 /)$.

\begin{abstract}
Stratiform clouds with embedded convective cells is an important precipitation system Precise knowledge of the cloud's microphysical structure can be useful for the development of a numerical weather prediction model and precipitation enhancement. Airborne measurement is one of the important ways for determining the microphysical structure of clouds. However, cloud particle shattering during measurement poses a serious problem to the measured microphysical characterization of clouds. In order to study the different influences of the shattered ice particles on the standard cloud imaging probe (CIP) measurement in the stratiform cloud region and the convective cloud region, a time-variant threshold method to identify the shattered fragments is presented. After application of this algorithm, the shattered fragments were recognized and their impacts on the particle size distribution (PSD), particle number concentration and ice water content measurement were analyzed. It was found that the shattering effect on the PSD decreases with the increasing size of less than $400 \mu \mathrm{m}$, fluctuates between $400 \mu \mathrm{m}$ and $1000 \mu \mathrm{m}$ and slightly increases with the increasing size of larger than $1000 \mu \mathrm{m}$ on average in a stratiform region and a convective region. However, the average ratio of PSD uncorrected to that corrected for shattering events using the presented algorithm in convective clouds is larger than that in the stratiform regions in the whole size, and nearly twice that in the size of less than $1000 \mu \mathrm{m}$. The measured number concentration can be overestimated by up to a factor of 3.9 on average in a stratiform region, while in a convective region, it is 7.7 , nearly twice that of a stratiform region. The ice water content in a stratiform region can be overestimated by $29.5 \%$ on average, but by $60.7 \%$ in a convective region. These findings can be helpful for the cloud physics community to use the airborne CIP measurement data for numerical weather and climate models.
\end{abstract}

Keywords: stratiform cloud; embedded convection; shattered particle; cloud microphysics measurement

\section{Introduction}

Stratiform clouds with embedded convective cells constitute an important precipitation system, which is also one of the main cloud types in weather modification [1,2]. Due to high ice crystal concentrations and supercooled water content in the embedded convection regions $[3,4]$, these systems can improve the precipitation efficiency of stratiform clouds by up to $20-35 \%[5,6]$ and also make its precipitation formation process more complex than that of stratiform clouds. Although there have been many field campaigns designed to observe microphysical processes in these clouds in detail, many microphysical processes in 
the clouds are not fully understood, which leads to great uncertainty in the representation of these clouds in the cloud model and the numerical weather forecast model [7-9].

Airborne measurement is one of the important observation ways to acquire the true microphysical structure of these cloud systems, which is helpful in understand the occurrence and development processes in the cloud. The cloud microphysical processes, especially the changing processes of ice crystal particle's size and habits, are mainly observed with airborne cloud particle measurement probes, especially the cloud imaging probe (CIP) produced by Droplet Measurement Technologies Inc. (Longmont, CO, USA) (DMT). The data from CIPs are also used in the validation of remote sensing [10-12]. However, the studies presented by Korelev et al. $[13,14]$ demonstrated that cloud particles could impact the probe's arms or tips or interact with turbulence and wind shear generated by the probe housing and shatter into many fragments. Then, the shattering artifacts could be swept into the probe sample volume and affect particle measurements, resulting in artificially high concentrations of small ice. While analyzing the relationship between the ice crystal number concentration and temperature, Gultepe et al. [15] found large concentrations of small ice particle existed and suggested improving the analysis.

To study and reduce the effect of shattering, Field et al. [16] analyzed the interarrival times of particles measured by optical array probes and found a bimodal structure. The long interarrival time mode represented the real cloud structure while the short interarrival time mode resulted from fragments of shattered ice particles. Then, they used the interarrival time threshold method to identify the shattered fragments and study the effects of shattering on measurements. Korolev et al. [17] proposed an improved probe tip structure and found that modified tips can greatly reduce the shattered fragments bouncing into the sample volume. Then, Korolev et al. [18] quantitatively studied the shattering effects on size distribution, number concentration, extinction coefficient and ice water content using OAP-2DC, CIP and FSSP measurements. After that, Jackson et al. [19,20] examined the impacts of shattering artifacts on size distribution function, bulk microphysical and scattering properties measured by a standard OAP-2DC and a modified probe. It is quite clear that the existing studies focused on the method to identify and reduce the particle shattering event and its influence on the measurements. However, the differences in the shattering effect during measurement in the stratiform cloud region and the convective cloud region have not been documented yet.

In China, most of the airborne imaging probes are of the standard form [21], and quite a significant number of cloud microphysical field measurements have been carried out in stratiform clouds with embedded convective cells at the service of weather modification in the past 15 years [22-24]. As a stratiform cloud with an embedded convective cell can produce more ice crystals and have a higher precipitation efficiency $[25,26]$, the precise knowledge of the cloud and precipitation microphysical processes is very helpful for the exploitation of cloud and air water resources in the sky. Hence, it is very important to answer the following question:

What is the difference in the shattering effects on the standard CIP measurements in the stratiform cloud region and the convective cell region?

This paper is organized as follows: Section 2 describes the probe and the data used in this study; Section 3 introduces the method used to identify the shattering artifacts; Section 4 presents the results of the effect of shattering on CIP measurements; Section 5 discusses the different results of applying the time-variant inter-arrival time threshold method and a fixed threshold method and the existence of small particles; the principal findings of the study are summarized in Section 6.

\section{Instrument and Data}

The data used in this study were from the Beijing Cloud Experiment (BCE), which was conducted from April to May 2009 in the upstream area of Beijing, Zhangjiakou area [27]. Throughout the experiment, three research aircrafts measured the cloud microphysical structure features simultaneously at different altitudes $[4,27]$. The three research airplanes 
were the Cheyenne III-A from the Shijiazhuang Weather Modification Office (number 3625), the Y-12 from the Beijing Weather Modification Office (number 3830) and the Shanxi Weather Modification Office's Y-12 (number 3817). Every plane was equipped with a suite of cloud and precipitation microphysics detection instruments, but only the planes 3830 and 3817 had an OAP-CIP. Although a CIP was installed on plane 3830, it measured the lowest part of the cloud, and most of the time plane 3830 flew in the liquid layer of the cloud during measurements. Hence, only the data from the Shanxi' Y-12 airplane were utilized to analyze the different effects of ice crystal shattering on the CIP measurements in the stratiform cloud region and the convective cell region.

During the $\mathrm{BCE}$ experiment, there were two cold-frontal systems passing through the field observation area on 18 April and 1 May 2009, respectively, and the dominant cloud type over the study zone was stratiform clouds with embedded convection. During the two exploration flights, the Shanxi's Y-12 mainly flew at $4200 \mathrm{~m}$ and the temperature in the detection cloud area was $-4 \sim-5^{\circ} \mathrm{C}$ and $-7.2 \sim-11.6^{\circ} \mathrm{C}$, respectively.

In the work of Zhu et al. [4], they used radar reflectivity and LWC to identify the stratiform clouds and embedded convection regions. In that study, the particle diameter measured by the CIP and PIP were also selected to identify the cloud regions. Using this method, the cloud regions during the flight time 17:41:00-17:54:00 on 18 April and 09:23:00-10:35:00 on 1 May 2019 were selected to study the shattering influence in different cloud types. The identified stratiform clouds and the embedded convection regions and their corresponding flight times are listed in Table 1. According to Table 1, there were two short stratiform cloud regions and one short convective cloud region on 18 April, and three short stratiform cloud regions and four convective cloud regions on 1 May. Some snapshot particle images during measurements in the identified cloud regions are shown in Figure 1, which suggests that the measurements were carried out in an ice cloud during the selected time.

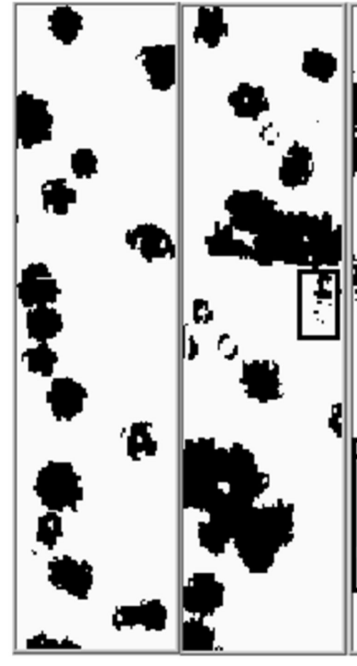

(a) (b) (c)

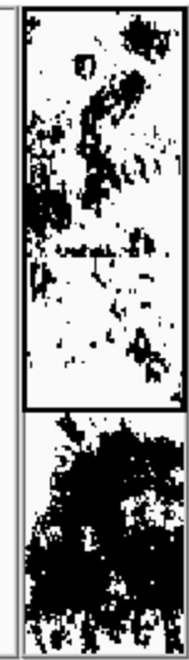

(d)

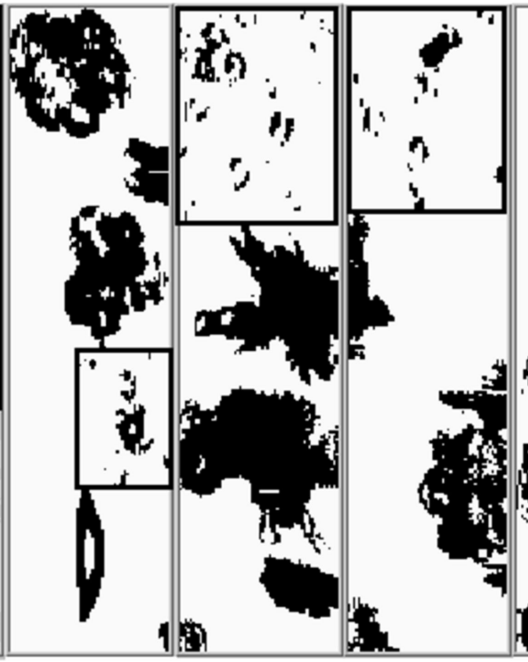

(g) (e)

(f)

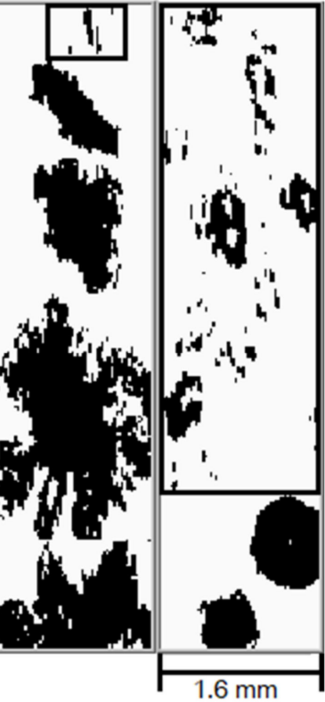

(i)

(j)

Figure 1. Cloud particle images measured by a CIP in the selected time; the shattered particles are highlighted in black boxes: (a) S1; (b) C1; (c) S2; (d) S3; (e) C2; (f) S4; (g) C3; (h) C4; (i) S5; (j) C5. 
Table 1. The identified cloud regions in the selected time.

\begin{tabular}{cccc}
\hline Flight & Time $\mathbf{B T}^{\mathbf{1}}$ ) & Cloud & Code \\
\hline 20090418 & $17: 44: 30-17: 46: 30$ & Stratiform & S1 \\
20090418 & $17: 48: 00-17: 50: 00$ & Convective & C1 \\
20090418 & $17: 51: 00-17: 54: 00$ & Stratiform & S2 \\
20090501 & $09: 23: 00-09: 25: 00$ & Stratiform & S3 \\
20090501 & $09: 30: 00-09: 32: 00$ & Convective & C2 \\
20090501 & $09: 46: 00-09: 51: 00$ & Stratiform & S4 \\
20090501 & $09: 38: 00-09: 39: 00$ & Convective & C3 \\
20090501 & $09: 51: 00-09: 52: 00$ & Convective & C4 \\
20090501 & $10: 17: 00-10: 22: 30$ & Stratiform & C5 \\
20090501 & $10: 25: 00-10: 26: 30$ & Convective & \\
\hline
\end{tabular}

${ }^{1}$ BT: Beijing Time.

\section{Time-Variant Interarrival Time Threshold Method}

During measurement, once a cloud particle enters the CIP's sampling area, its image with its arrival time is sampled and recorded. The arrival time difference between two continuous cloud particles is called the interarrival time (IAT). The frequency distributions of cloud particles' IATs in the cloud regions $\mathrm{S} 1$ and $\mathrm{C} 1$ are shown in Figure 2, which clearly show that the distributions both have bimodal characteristics. Field et al. [16] demonstrated that the long interarrival time mode represents the real cloud structure while the short interarrival time mode results from fragments of shattered ice particles, and the fragmented particles can be filtered using an interarrival time threshold.
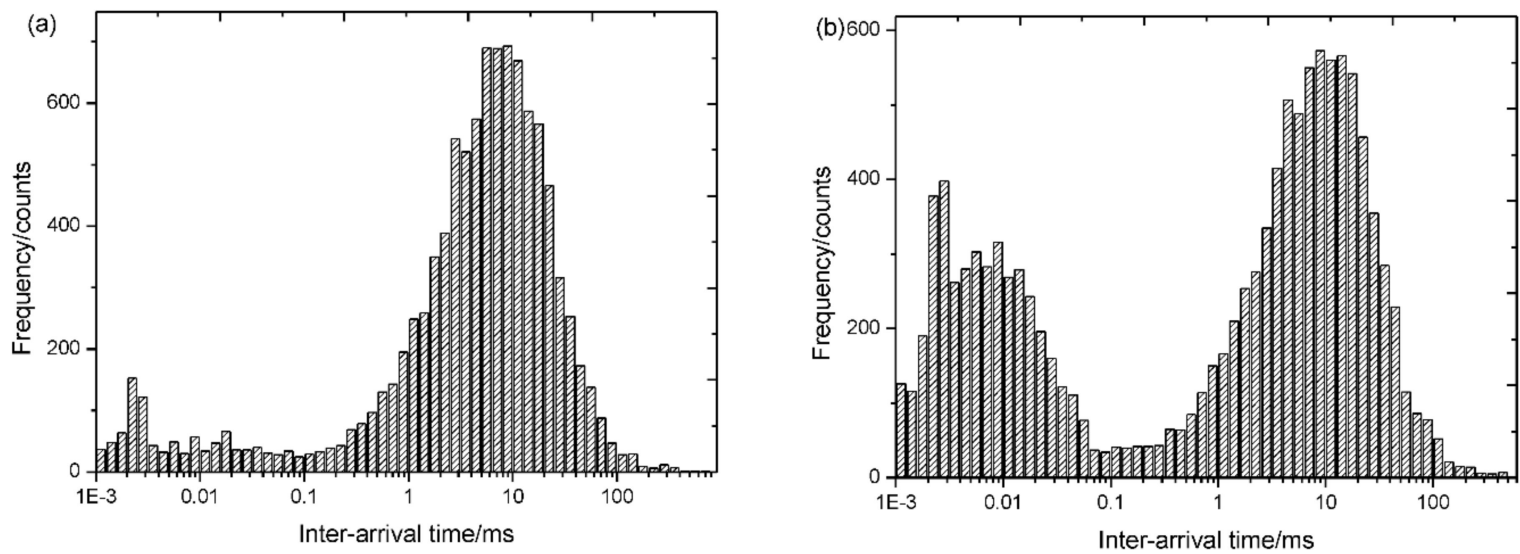

Figure 2. Statistics of the cloud particle interarrival time at the selected time (a) S1; (b) C1.

The method using the interarrival time threshold is called the interarrival time algorithm; it is based on a bimodal Poisson probability density function and describes the bimodal distribution of cloud particles' IATs. The threshold through this algorithm is chosen to remove most artifacts and conserve as many as possible naturally occurring particles. However, until now, there is still no uniform standard for threshold determination. It can be determined with the smallest measured frequency of occurrence or the smallest frequency of occurrence based on fit curves to the bimodal distribution of the whole flight or a specific number of sequentially observed particles, or a flexible timeframe [28]. In fact, the concentration of cloud particles in different parts of the cloud is different, and the concentration difference between clouds is even greater, which means that the threshold determined on the basis of a whole flight or a fixed particle number or a fixed timeframe is not optimal, especially when measured in a stratiform cloud with embedded convection. To solve this problem, we present a time-variant interarrival time threshold method using the following procedures:

1. The data for analysis are read and the arrival time of the particle is extracted. 
2. Taking $10 \mathrm{~s}$ as a statistical period and on the premise that the number of particles meets the statistical requirements, the interarrival time of the particles is counted in the form of histogram statistics.

3. The distribution of the particles' interarrival time is fitted using a polynomial fitting method.

4. If the fitted mode is consistent with a double mode, the threshold of the interarrival time can be determined as twice the peak value in the short mode.

5. Then, the shattered fragments in the statistical period can be identified using the determined threshold.

The threshold from the above method is determined through the constraints on the timescale and particle number, which is more of a statistical significance and conforms to the actual physical condition. The time period is selected as $10 \mathrm{~s}$ because the data measured using an airborne cloud imaging probe generally needs to be further averaged to obtain a representative value on a longer timescale. According to the existing literature, this timescale can be $10 \mathrm{~s}, 20 \mathrm{~s}$ or $60 \mathrm{~s}$, which is related to the specific research situation $[29,30]$. Therefore, in order to meet the requirement of statistics, it is necessary to identify the shattered fragments on the timescale of statistics. Indeed, the shorter the timescale for statistics, the more favorable the true value obtained from the statistics. However, the number of samples may not be enough and the time for operation inevitably increases if the timescale for statistics becomes shorter. Hence, $10 \mathrm{~s}$ is a better compromise. The selection of the particle number is based on the sample number requirement for statistics. Generally, the larger the sample number is, the better the true value can be acquired, and it should be not less than 100 . However, considering the statistical timescale, the sampling volume of the probe and the concentration of ice particles in the cloud, the particle number for statistics is set to 600 .

The fitting formula for the IATs distribution histogram is as follows:

$$
f_{i}=\sum_{j=0}^{m} a_{j} x_{i}^{j}+C
$$

where $f_{i}$ is the fitting series, $x$ is the IAT series, $a$ is the coefficient of the polynomial, $m$ is the order of the fitting polynomial, $C$ is the minimum between two modal peaks.

Using the above mentioned method to obtain the time interval thresholds of S1 and $\mathrm{C} 1$ and the first short period of the IATs distribution histogram and its fitness curve are shown in Figure 3. The thresholds for the first short period in S1 and C1 were $0.01 \mathrm{~ms}$ and $0.02 \mathrm{~ms}$, respectively.
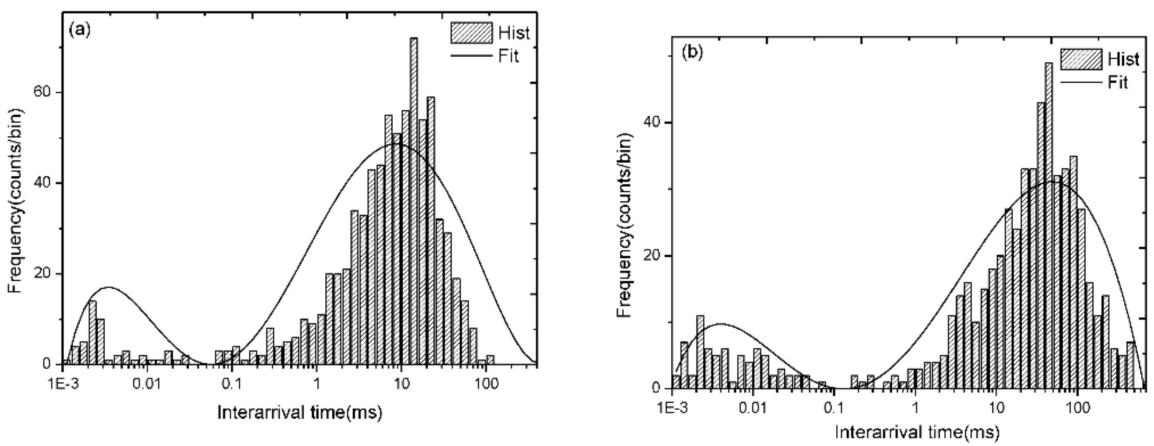

Figure 3. Interarrival time statistics and curve fit results of the first short period in S1 and C1: (a) S1; (b) $\mathrm{C} 1$.

\section{Shattering Effects on the Cloud Microphysical Parameters Measurement}

Cloud microphysical parameters are the parameters characterizing the micro characteristics of clouds. Obtaining accurate cloud microphysical information is the premise of understanding the physical development processes of cloud precipitation. Therefore, study- 
ing the influence of unnatural shattering events on the cloud microphysical measurement is beneficial for the accurate knowledge of the cloud and precipitation microphysics. Before the study, it is necessary to eliminate other forms of pseudoparticles. Here, the method proposed by Huang et al. [31] was used to eliminate other forms of pseudo particles, for example, the streakers and image frames with multiple particles.

\subsection{Effects on Cloud Particle Size Distribution}

Cloud particle size distribution is the most basic microphysical attribute of cloud precipitation particle population which is used to represent the number of cloud particles on different scales within a certain volume. The evolution of cloud precipitation particle spectrum reflects the development and change process of the cloud and precipitation, and it can be calculated as follows:

$$
P S D_{i}=\frac{N_{i}}{V_{\text {samp }} \Delta r}
$$

where $P S D_{i}$ is the particle size distribution between the sizes of $r_{i} \sim r_{i}+\Delta r, \Delta r$ is the interval of the particle size, $N_{i}$ is the number of particles of the size of $r_{i} \sim r_{i}+\Delta r, V_{\text {samp }}$ is the sample volume.

The ratios of particle size distribution uncorrected and corrected for shattering events using the algorithm above in the stratiform cloud region and the convective region are shown in Figure 4. The maximum of the ratio can be more than 10 in the stratiform cloud region and near 16 in the convective region. It is shown clearly in Figure 4 that the effect of shattering on particle size distribution in most of the selected cloud regions decreases with the increasing size below $800 \mu \mathrm{m}$ and slowly increases with the increasing size above $800 \mu \mathrm{m}$. This may be related to the generation of a large fragment and many small fragments when the cloud particle shatters [21]. It can also be seen that the ratio has a great fluctuation in the cloud regions of S3, C3 and C5 above $300 \mu \mathrm{m}$.
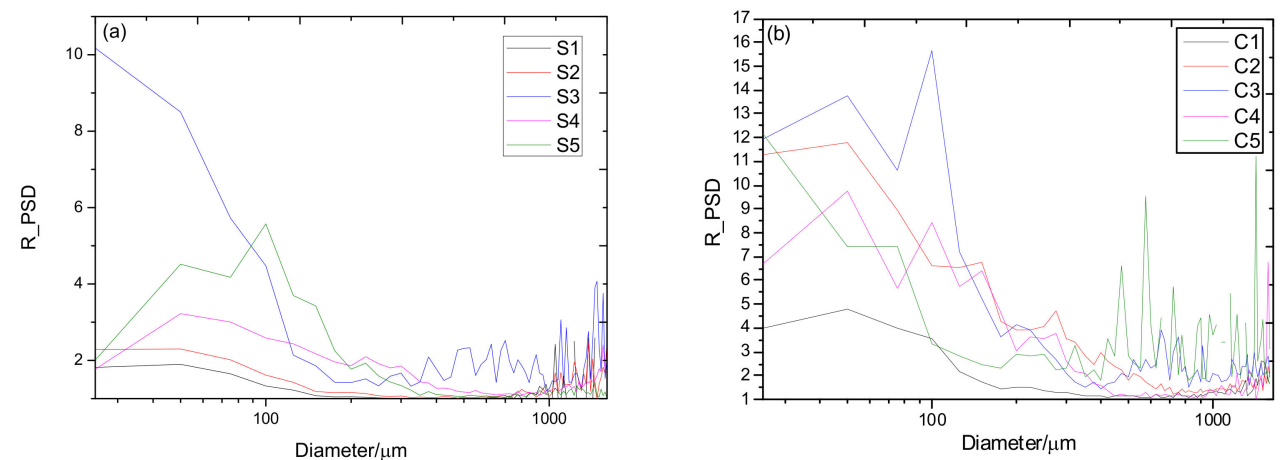

Figure 4. Ratio distribution of the cloud particle number concentration with diameter in different cloud types: (a) stratiform; (b) convective.

To reduce the fluctuations of the shattering influence in the selected zones, the ratio of particle size distribution in the selected stratiform cloud regions and the convective cloud regions was averaged respectively. The average result is shown in Figure 5. It is clearly shown that the maximum average ratio is 9.5 in the convective regions and 4.5 in the stratiform clouds, both in the bin of $50 \mu \mathrm{m}$. It can also be seen that the two average ratios in the selected cloud regions both decrease with the increasing size of less than $400 \mu \mathrm{m}$, fluctuate between $400 \mu \mathrm{m}$ and $1000 \mu \mathrm{m}$ and slightly increase with the increasing size of larger than $1000 \mu \mathrm{m}$. However, the average ratio of the convective clouds was larger than that of the stratiform regions in the whole size, and nearly twice that in the size of less than $1000 \mu \mathrm{m}$. Apparently, the effect of shattering on particle size distribution is more serious in a convective cloud than that in a stratiform cloud, especially in the size of less than $1000 \mu \mathrm{m}$. The findings here are quite different from the results in the works conducted by Gultepe et al. (2001) [15] where the authors said that there is no change in $N_{i}$ of sizes $>100$ microns when the shattered particles are removed. It is also 
slightly different from the results in the works conducted by Korolev et al. (2013) [18] and Jackson et al. (2014) [19] which show that the shattering artifacts mainly affect particles smaller than approximately $500 \mu \mathrm{m}$. Such difference is not contradictory because their works did not specifically consider the stratiform cloud region and the convective cloud region, respectively.

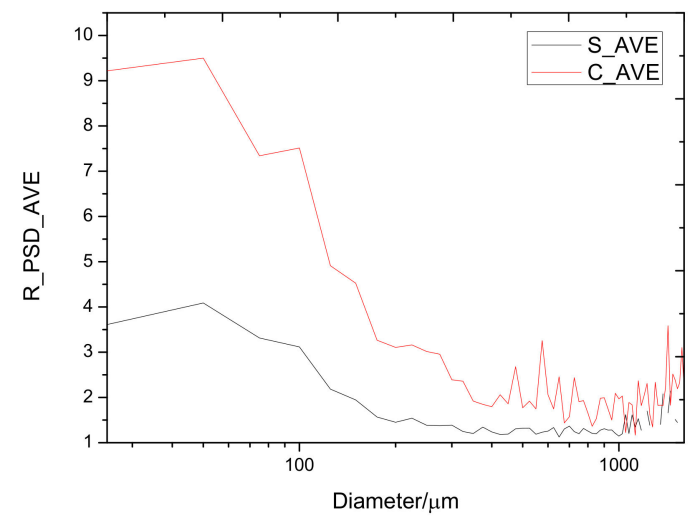

Figure 5. Ratio of the average distribution of the cloud particle number concentration with diameter in different cloud types.

\subsection{Effects on the Particle Number Concentration}

The particle number concentration represents the total number of particles per unit volume, which is calculated as follows:

$$
N_{d}=N_{n} / V_{\text {samp }}
$$

where $N_{d}$ is the particle number concentration, $N_{n}$ is the count of particles and $V_{\text {samp }}$ is the sample volume of the probe.

The ratios of the particle number concentration uncorrected and corrected for shattering events using the algorithm above in the stratiform cloud region and the convective region were calculated and the statistical variables (maximum value, first quartile (Q1), median value $(\mathrm{Q} 2)$, third quartile $(\mathrm{Q} 3)$, minimum and mean values) of the ratio in each selected cloud region are shown in Figure 6. As seen in Figure 6a, the maximum ratio in the stratiform cloud region can be as large as 24 in S5, but the median and mean values are all less than 5 except that of S3. In Figure 6b, the maximum ratio in the selected convective regions is 22.1 from $C 5$ and the median and mean values are all larger than 5 except that of C1. The larger maximum in stratiform clouds implies the complexity of shattering, and sometimes some certain factors, for example, particle shape and size, cause the event to happen more frequently and shattering into more small fragments.
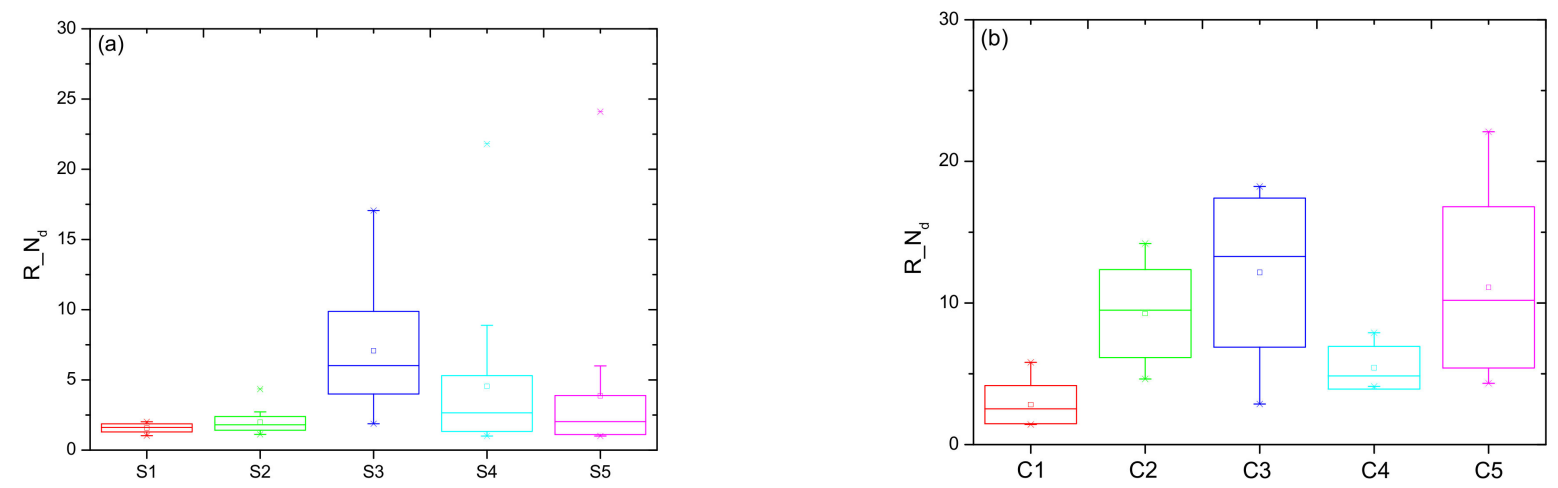

Figure 6. Statistics of $R \_N_{d}$ in the selected cloud area: (a) stratiform; (b) convective. 
To further investigate which type of clouds is more seriously influenced by shattering, the ratios of the five stratiform cloud regions were combined together for statistics, and such an operation was also performed on the ratios of the five convective cloud regions. The statistical results are shown in Figure 7 and listed in Table 2. Though the maximum (22.1) of the convective clouds was a little less than that of the stratiform clouds (24.1), the other five statistical variables of convective clouds were all higher than those of the stratiform clouds, indicating that the influence of shattering events on the particle number concentration in the convective cloud region was greater than that in the stratiform region. On average, the influence on the number concentration measurement in the convective regionwas twice $(7.75 / 3.86)$ that in the stratiform cloud region, and the difference was even larger in terms of the median value: the influence in the convective region was nearly three $(6.61 / 2.02)$ times that in the stratiform cloud region.

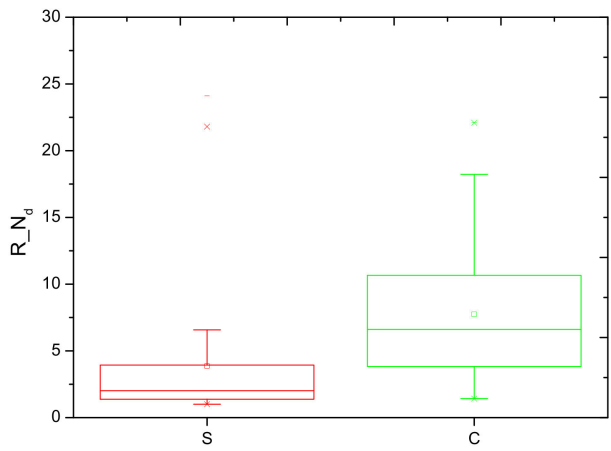

Figure 7. Statistics of $R_{-} N_{d}$ in the stratiform cloud region and the convective cloud region.

Table 2. Statistical information for $R_{-} N_{d}$ of the stratiform region and the convective region.

\begin{tabular}{ccccccc}
\hline Cloud & Mean & Q1 & Minimum & Median & Q3 & Maximum \\
\hline Stratiform & 3.86 & 1.38 & 1.00 & 2.02 & 3.94 & 24.10 \\
Convective & 7.75 & 3.83 & 1.42 & 6.61 & 10.66 & 22.09 \\
\hline
\end{tabular}

\subsection{Effects on the Ice Water Content}

The ice water content (IWC) was calculated as follows:

$$
I W C=\frac{1}{L} \sum_{j} \frac{m_{j}}{S_{j}}
$$

where $L$ is the flight distance during measurement, $S_{j}$ is the sampling area related to the particle size and $m_{j}$ is the mass of ice particles corresponding to the particle size, which can be calculated using the mass dimension relationship method as shown in the following equation:

$$
m_{j}=a D_{j}^{b}
$$

where $m_{j}$ is the particle mass, $D_{j}$ is the particle size, $a$ and $b$ are coefficients with the values of $7.38 \times 10^{-11}$ and 1.9 , respectively.

The ratios of the IWC uncorrected and corrected for shattering events using the algorithm above were calculated. Though the ice mass calculations from the CIP alone may result in underestimation of the IWC due to the existence of large ice particles outside its size measurement range, the method to recalculate the particle size and sampling area suggested by Heymsfield and Parrish [32] and improved by Huang and Lei [33] was used to compensate for the lost part. Hence, the ratios of the IWC uncorrected and corrected for shattering events using the suggested algorithm can still clearly reflect the influence of shattering on the CIP IWC measurement. The maximum value, the first quartile (Q1), the median value $(\mathrm{Q} 2)$, the third quartile $(\mathrm{Q} 3)$, the minimum and the mean values of the 
ratios in each selected stratiform cloud and convective region were counted and are shown in Figure 8.
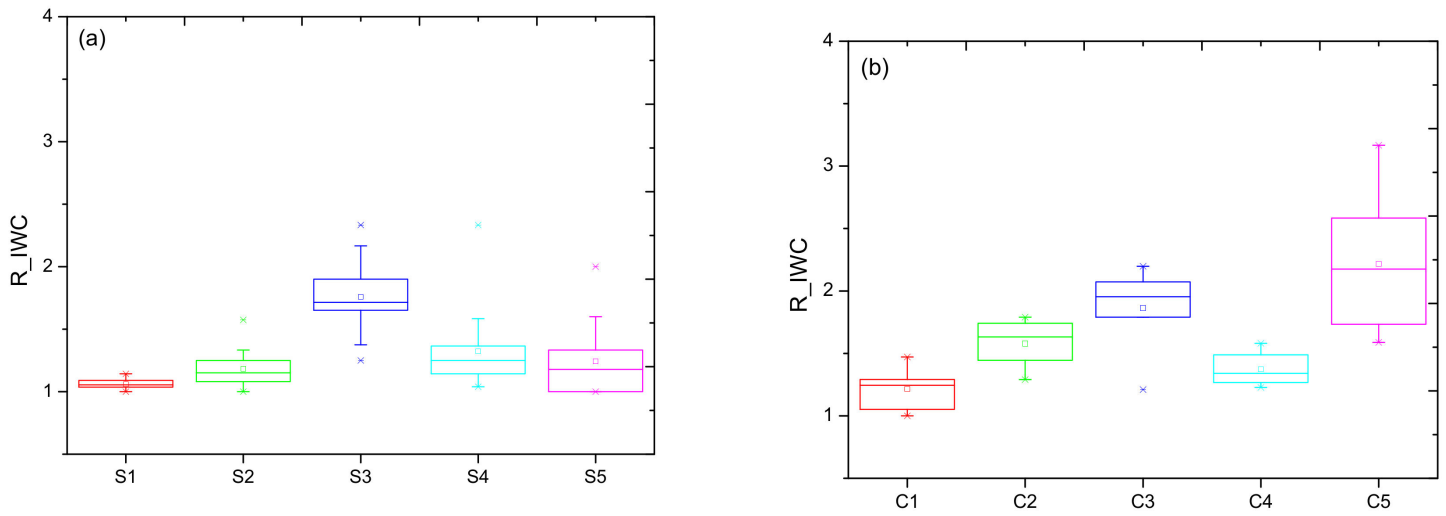

Figure 8. Statistics of $R \_I W C$ in the selected region: (a) stratiform; (b) convective.

It can be seen from Figure 8a that the shattering effect on the IWC measurement in stratiform clouds was not so significant as that on the number concentration. As seen in Figure 8a, the maximum ratio in the stratiform cloud region is in S3, which is less than 2.5. In Figure $8 \mathrm{~b}$, the maximum ratio in the selected convective regions is in $\mathrm{C} 5$, which is larger than 3. The larger maximum of the IWC ratio in $\mathrm{C} 5$ does not contradict the larger maximum number concentration ratio in $\mathrm{S} 3$ because the IWC is primarily determined by larger particles.

To further investigate the shattering effect on the IWC measurement in different types of clouds, the ratios of the five stratiform cloud regions were combined together as a whole and such an operation was also performed on the ratios of the five convective cloud regions. The statistical results are shown in Figure 9 and listed in Table 3. It can be seen that except the minimum value, the other five statistical variables of convective clouds were all higher than those of the stratiform clouds, indicating that the influence of shattering events on the ice water measurement in the convective cloud region was greater than that in the stratiform region. On average, the contribution of shattering on the CIP IWC measurement in aconvective region is $1.2(1.61 / 1.29)$ times that in a stratiform cloud region.

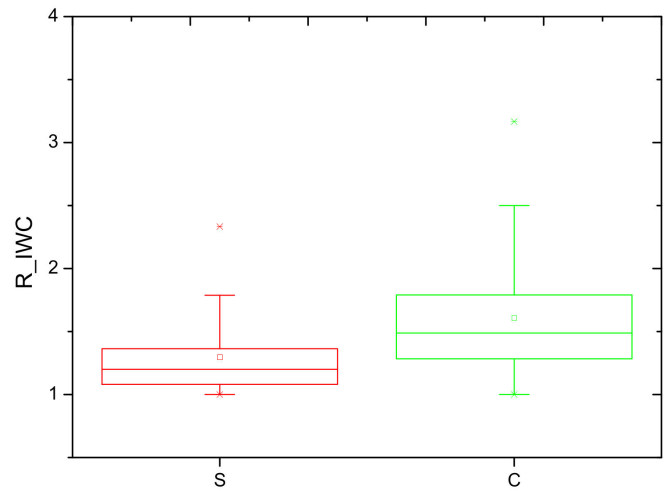

Figure 9. Statistics of $R_{-} I W C$ in the stratiform cloudregion and the convective cloud region.

Table 3. Statistical information for $R \_I W C$ of the stratiform region and the convective region.

\begin{tabular}{ccccccc}
\hline Cloud & Mean & Q1 & Minimum & Median & Q3 & Maximum \\
\hline Stratiform & 1.29 & 1.08 & 1.00 & 1.20 & 1.36 & 2.33 \\
Convective & 1.61 & 1.28 & 1.00 & 1.49 & 1.79 & 3.17 \\
\hline
\end{tabular}




\section{Discussion}

\subsection{The Interarrival Time Threshold}

The interarrival time method (IAT) has been proved to be an effective method to remove the shattering artifacts in the OAP data $[18,19]$. One of the key steps to realize the IAT algorithm is to determine the threshold value. Some algorithms define a single threshold representative of the whole flight [24,31], others use a specific number of sequentially observed particles, a fixed timeframe or a flexible timeframe for defining the temporal variation [28]. To illustrate the different results of applying corrections with the time-variant threshold and the fixed threshold, the data of cloud regions S1 and C1, the presented time-variant threshold method in this research and the fixed threshold method $[24,31]$ were selected. The results of segregating the intact particles and shattering artifacts performed using the time-variant threshold and the fixed threshold are shown in Figure 10. It is clearly shown that there is a significant decrease in the small ice particles (S1: $<200 \mu \mathrm{m}$; $\mathrm{C} 1:<300 \mu \mathrm{m})$ after applying the IAT method. In the S1 region, the fixed threshold method seems to reject a little more artifacts than the time-variant threshold method. In the C1 region, the results of the two methods seem to overlap each other. Such a comparison result could not give us a clear answer regarding which method was better because the true real value was unknown. The threshold depends on many microphysical, environmental and instrumental parameters, especially the particle concentration and the airplane speed. As the particle concentration in the cloud and the aircraft speed could not remain approximately constant during the whole flight, the fixed threshold was to inevitably miss or falsely identify shattered fragments. The comparison of the algorithms' advantages was not the aim of this research; however, the similar results of the two methods give us confidence in the results of this research.
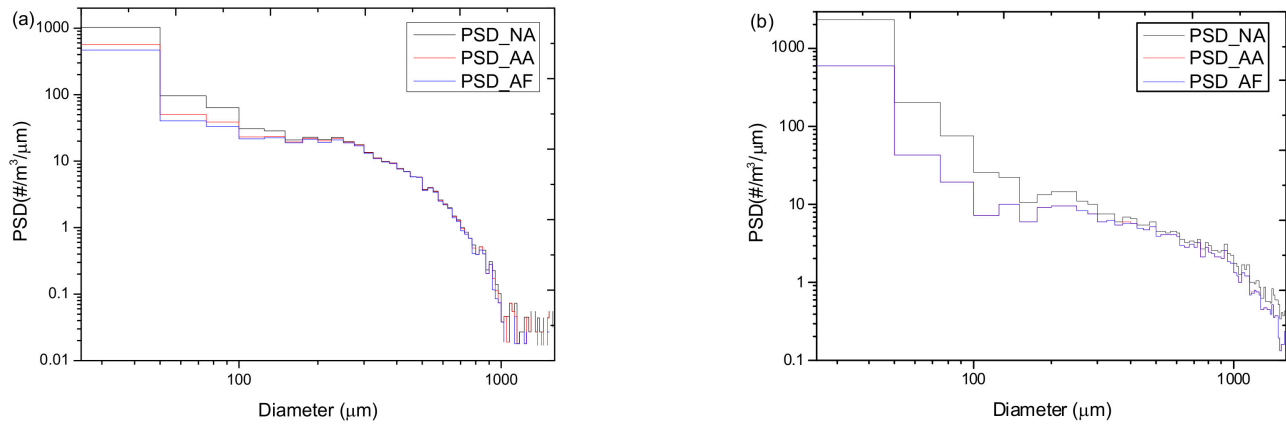

Figure 10. Comparisons of particle concentration distribution measured by a standard CIP before (black, PSD_NA) and after interarrival time corrections with a time-variant threshold (red, PSD_AA) and a fixed threshold (blue, PSD_AF), (a) S1, (b) C1.

\subsection{Small Ice Particles}

Small ice particles may play a significant role in radiation transfer and precipitation formation and debates on their omnipresence in ice clouds have existed for more than 30 years since the application of OAPs in cloud airborne measurements in 1970s [18]. Figure 10 shows that there are still some concentrations at the smallest size after applying the shattering removal method. However, small ice crystals rarely exist in precipitating clouds (Gultepe et al., 2019) [34]. As suggested by Korolev et al. [17,18], ITA alone is unable to filter out all shattering artifacts and the best strategy to remove the shattered fragments is to combine the modified tips and the post-processing method. Hence, it can be definitively stated that these small particles are not all real. Except for shattering, these small ice particles can be subject to out-of-focus errors away from the object plane and sizing and to counting errors due to the discrete nature of particle sizing [18]. Hence, caution is needed with these small ice crystals, especially those with $\sim 4$ pixel-size particles. It may be better to remove small ice crystals of size less than $100 \mu \mathrm{m}$. 


\section{Conclusions}

To obtain the difference of the shattering effects on the standard CIP measurements in the stratiform cloud region and the convective cell region, a time-variant interarrival time threshold method is presented to identify the particle shattering events, and the data from the Beijing Cloud Experiment were used to help determine the different effects. The analysis of the cloud microphysical measurement results with and without applying the filtering algorithm yielded the following important conclusions:

1. The effect of shattering on particle size distribution decreases with the increasing size below $400 \mu \mathrm{m}$, fluctuates between $400 \mu \mathrm{m}$ and $1000 \mu \mathrm{m}$ and slightly increases with the increasing size of larger than $1000 \mu \mathrm{m}$. However, the average ratio of the convective clouds is larger than that of the stratiform regions in the whole size, and nearly twice that in the size of less than $1000 \mu \mathrm{m}$.

2. Shattered fragments may increase the measured particle number concentration by up to one or two orders of magnitude. In terms of stratiform and convective regions, the influence of shattering events on the particle number concentration in a convective cloud region is greater than that in a stratiform region. On average, the influence on the number concentration measurement in a convective region is 1.5 times that in a stratiform cloud region, and the median difference is even larger: the influence in a convective region is nearly three times that in a stratiform cloud region.

3. In terms of the effect of shattering on the ice water content measurement, the influence of shattering events on the ice water measurement in a convective cloud region is greater than that in a stratiform region. On average, the contribution of shattering on the CIP IWC measurement in a convective region is 1.2 times that in a stratiform cloud region.

Hence, the effects of ice particle shattering on the same microphysical parameter measurement in different cloud regions are different, and they are greater in a convective region than in a stratiform cloud; in the same cloud area, the effects on the measurement of different parameters are also different: theyare greater with regard to the number concentration measurement than to the ice water content measurement. Korolev et al. [18] demonstrated that the effect of shattering is complex and depends on a large variety of parameters associated with the microphysical properties of particles, environmental conditions and the sampling arrangement. Different effects should be attributed to the more complex dynamic conditions and microphysical conditions in convective cloud regions in comparison with stratiform regions and to the formation of many small fragments when the cloud particle shatters. The conclusions of this study not only help to understand the uncertainty of the standard CIP measurement in two different cloud environments, but also help to better understand the defects of the historical data measured by standard CIPs in cloud microphysics research and numerical model development.

Funding: This work was supported by the National Key R\&D Program of China (grant No. 2018YFC1507900), the National Natural Science Foundation of China (grant Nos. 41775166, 41705142), the program of the Key Laboratory of Meteorological Disasters (KLMD), the Ministry of Education and the Collaborative Innovation Center on Forecast and Evaluation of Meteorological Disasters (CIC-FEMD), Nanjing University of Information Science and Technology, Nanjing, China (grant No. KLME201907), the joint program from Jiangsu Key Laboratory of Meteorological Observation and Information Processing and Jiangsu Technology and Engineering Center of the Meteorological Sensor Network, Nanjing University of Information Science and Technology, Nanjing, China (grant No. KDXS1803).

Institutional Review Board Statement: Not applicable.

Informed Consent Statement: Not applicable.

Data Availability Statement: Not applicable.

Conflicts of Interest: The author declare no conflict of interest. 


\section{References}

1. Yanchao, H. The numerical simulation on study of convective and stratiform mixed clouds, part(I)-The model and paramterization of microphysical processes. Acta Meteorol. Sin. 1996, 5, 54544-54557. (In Chinese)

2. Huang, M.Y.; Hong, Y.C.; Xu, H.Y. The effects of the existence of stratiform cloud on the development of cumulus cloud and its precipitation. Acta Meteorol. Sin. 1987, 45, 72-77. (In Chinese)

3. Evans, A.G.; Locatelli, J.D.; Stoelinga, M.T.; Hobbs, P.V. The IMPROVE-1 storm of 1-2 February 2001. Part II:Cloud structures and the growth of precipitation. J. Atmos. Sci. 2005, 62, 3456-3473. [CrossRef]

4. Shichao, Z.; Xueliang, G.; Guangxian, L.; Lijun, G. Ice crystal habits and growth processes in stratiform clouds with embedded convection examined through Aircraft Observation in Northern China. J. Atmos. Sci. 2015, 72, 2011-2032.

5. Hallett, J. Production of secondary ice particles during the riming process. Nature 1974, 249, 26-28. [CrossRef]

6. Rangno, A.L.; Hobbs, P.V. Microstructures and precipitation development in cumulus and small cumulonimbus clouds over the warm pool of the tropical Pacific Ocean. Q. J. R. Meteorol. Soc. 2005, 131, 639-673. [CrossRef]

7. Morrison, H.; McCoy, R.B.; Klein, S.A.; Xie, S.C.; Luo, Y.L.; Avramv, A.; Chen, M.X.; Cole, J.N.S.; Falk, M.; Foster, M.J.; et al. Intercomparison of model simulations of mixed-phaseclouds observed during the ARM mixed-phase arctic cloud experiment. II: Multilayer cloud. Q. J. R. Meteorol. Soc. 2009, 135, 1003-1019. [CrossRef]

8. Luo, Y.; Wang, Y.; Wang, H.; Zheng, Y.; Morrison, H. Modeling convective-stratiform precipitation processes on a Mei-Yu front with the Weather Research and Forecasting model: Comparison with observations and sensitivity to cloud microphysics parameterizations. J. Geophys. Res. 2010, 115, D18117. [CrossRef]

9. Hou, T.J.; Lei, H.C.; Hu, Z.X.; Yang, J.F.; Li, X.Y. Simulations of microphysics and precipitation in a stratiform cloud case over northern China: Comparison of two microphysics schemes. Adv. Atmos. Sci. 2020, 37, 117-129. [CrossRef]

10. Padmakumari, B.; Maheskumar, R.S.; Morwal, S.B.; Harikishan, G.; Konwar, M.; Kulkarni, J.R.; Goswami, B.N. Aircraft observations of elevated pollution layers near the foothills of the Himalayas duringCAIPEEX-2009. Q. J. R. Meteorol. Soc. 2013, 139, 625-638. [CrossRef]

11. Padmakumari, B.; Maheskumar, R.S.; Harikishan, G.; Kulkarni, J.R.; Goswami, B.N. Comparative study of aircraft- and satellitederived aerosol and cloudmicrophysical parameters during CAIPEEX-2009 over the Indian region. Int. J. Remote Sens. 2013, 34, 358-373. [CrossRef]

12. Min, Q.; Joseph, E.; Lin, Y.; Min, L.; Yin, B.; Daum, P.H.; Kleinman, L.I.; Wang, J.; Lee, Y.-N. Comparison of MODIS cloud microphysical propertieswith in-situ measurements over the Southeast Pacific. Atmos. Chem. Phys. 2012, 12, 11261-11273. [CrossRef]

13. Korolev, A.V.; Isaac, G.A. Shattering during sampling by OAPs and HVPS. Part 1: Snow particles. J. Atmos. Ocean. Technol. 2005, 22, 528-542. [CrossRef]

14. Korolev, A.V.; Emery, E.F.; Strapp, J.W.; Cober, S.G.; Isaac, G.A.; Wasey, M.; Marcotte, D. Small ice particles in tropospheric clouds: Fact or artifact? Airborne icing instrumentation evaluation experiment. Bull. Am. Meteor. Soc. 2011, 92, 967-973. [CrossRef]

15. Gultepe, I.; Isaac, G.A.; Cober, S.G. Ice crystal number concentration versus temperature for climate studies. Int. J. Climatol. 2001, 21, 1281-1302. [CrossRef]

16. Field, P.R.; Heymsfield, A.J.; Bansemer, A. Shattering and Particle Interarrival Times Measured by Optical Array Probes in Ice Cloud. J. Atmos. Ocean. Technol. 2006, 23, 1357-1371. [CrossRef]

17. Korolev, A.V.; Emery, E.F.; Creelman, K. Modification and tests of particle probe tips to mitigate effects of ice shattering. J. Atmos. Ocean. Technol. 2013, 30, 690-708. [CrossRef]

18. Korolev, A.V.; Emery, E.F.; Strapp, J.W.; Cober, S.G.; Isaac, G.A. Quantification of the Effects of Shattering on Airborne Ice Particle Measurements. J. Atmos. Ocean. Technol. 2013, 30, 2527-2553. [CrossRef]

19. Jackson, R.C.; McFarquhar, G.M.; Stith, J.; Beals, M.; Shaw, R.A.; Jensen, J.; Fugal, J.; Korolev, A. An assessment of the Impact of antishattering tips and artifact removal techniques on cloud ice size distributions measured by the 2DC Cloud Probe. J. Atmos. Ocean. Technol. 2014, 31, 2567-2590. [CrossRef]

20. Jackson, R.C.; Mcfarquhar, G.M. An assessment of the Impact of antishattering tips and artifact removal techniques on bulk cloud ice microphysical and optical properties measured by the 2DC Cloud Probe. J. Atmos. Ocean. Technol. 2014, 31, 2131-2144. [CrossRef]

21. Minsong, H.; Hengchi, L.; Jiatian, C.; Xiaoqing, Z. Cloud particle shattering during sampling by airborne optical array probes. Chin. J. Atmos. Sci. 2016, 40, 647-656.

22. Zhao, Z.; Lei, H. Observed microphysical structure of nimbostratus innortheast cold vortex over China. Atmos.Res. 2014, 142, 91-99. [CrossRef]

23. Zhao, Z.; Lei, H. Aircraft observations of liquid and ice in mid-latitudemixed-phase clouds. Adv. Atmos. Sci. 2014, 31, 604-610. [CrossRef]

24. Jiefan, Y.; Hengchi, L.E.I.; Hou, T. Observational Evidence of High Ice Concentration in a Shallow Convective Cloud Embedded in Stratiform Cloud over North China. Adv. Atmos. Sci. 2017, 34, 509-520.

25. Hobbs, P.V.; Rangno, A.L. Rapid development of high ice particle concentrations in small polar maritime cumuliform clouds. J. Atmos. Sci. 1990, 47, 2710-2722. [CrossRef]

26. Hobbs, P.V.; Locatelli, J.D. Rainbands, precipitation cores and generating cells in a cyclonic storm. J. Atmos. Sci. 1978, 35, $230-241$. 
27. Lu, G.X.; Guo, X.L. Distribution and origin of aerosol and its transform relationship with CCN derived from the spring multiaircraft measurements of Beijing Cloud Experiment (BCE). Chin. Sci. Bull. 2012, 57, 2460-2469. [CrossRef]

28. McFarquhar, G.M.; Baumgardner, D.; Bansemer, A.; Abel, S.J.; Crosier, J.; French, J.; Rosenberg, P.; Korolev, A.; Schwarzoenboeck, A.; Leroy, D.; et al. Processing of Ice Cloud In-Situ Data Collected by Bulk Water, Scattering, and Imaging Probes: Fundamentals, Uncertainties and Effortstowards Consistency. Meteor. Monogr. 2017, 58, 11.1-11.33. [CrossRef]

29. Grosvenor, D.P.; Choularton, T.W.; Lachlan-Cope, T.; Gallagher, M.W.; Crosier, J.; Bower, K.N.; Ladkin, R.S.; Dorsey, J.R. In-situ aircraft observations of ice concentrations withinclouds over the Antarctic Peninsula and Larsen Ice Shelf. Atmos. Chem. Phys. 2012, 12, 11275-11294. [CrossRef]

30. Heymsfield, A.J.; Schmitt, C.; Bansemer, A. Ice cloud particle size distributions and pressure-dependent terminal velocities from in situ observations at temperatures from 0 to $-86^{\circ}$ C. J. Atmos. Sci. 2013, 70, 4123-4154. [CrossRef]

31. Huang, M.S.; Lei, H.C.; Jin, L. Pseudo Particle Identification in the image data from the Airborne Cloud and Precipitation Particle Image Probe. Chin. J. Atmos. Sci. 2017, 41, 1113-1124.

32. Heymsfield, A.J.; Parrish, J.L. A computational technique for increasing the effective sampling volume of the PMS twodimensional particle size spectrometer. J. Appl. Meteor. 1978, 17, 1566-1572. [CrossRef]

33. Huang, M.S.; Lei, H.C. Processing method for the partial particles and its influence on the cloud microphysical parameters measured by the airborne cloud and precipitation image probe. Acta Phys. Sin. 2018, 67, 249202.

34. Gultepe, I.; Heymsfield, A.J.; Field, P.R.; Axisa, D. Ice-phase precipitation. Meteor. Monogr. 2017, 58, 16.1-16.36. [CrossRef] 